Article

\title{
Synthesis of Three-Dimensionally Ordered Macroporous NiCe Catalysts for Oxidative Dehydrogenation of Propane to Propene
}

\author{
Kegong Fang ${ }^{1, *}+{ }^{(D)}$, Lulu Liu ${ }^{2,+}$, Mingwei Zhang ${ }^{1}$, Lu Zhao ${ }^{1}$, Juan Zhou ${ }^{1}$, Wenbin Li ${ }^{1}$, \\ Xiaoliang $\mathrm{Mu}^{1}$ and Cheng Yang ${ }^{3}$ \\ 1 State Key Laboratory of Coal Conversion, Institute of Coal Chemistry, Chinese Academy of Sciences, \\ Taiyuan 030001, China; zmwsdust@126.com (M.Z.); zhaolu@sxicc.ac.cn (L.Z.); \\ zhoujuan20091221@163.com (J.Z.); liwenbin@sxicc.ac.cn (W.L.); muxiaoliang_1986@163.com (X.M.) \\ 2 College of Environmental Engineering, Shanghai University, 333 Nanchen Road, Shanghai 200444, China; \\ lululiu123@126.com \\ 3 College of Chemistry and Chemical Engineering, University of Jinan, Jinan 250022, China; \\ chm_yangch@ujn.edu.cn \\ * Correspondence: kgfang@sxicc.ac.cn; Tel.: +86-351-406-4505 \\ + These authors contributed equally to this work and should be considered as co-first authors.
}

Received: 18 December 2017; Accepted: 8 January 2018; Published: 10 January 2018

\begin{abstract}
Three-dimensionally ordered macroporous (3DOM) NiCe catalysts with different $\mathrm{Ni} / \mathrm{Ce}$ molar ratio were fabricated using the colloidal crystal templating method. The physic-chemical properties of the samples were characterized by various techniques, including $\mathrm{N}_{2}$ adsorption-desorption, X-ray diffraction (XRD), transmission electron microscopy (TEM), Raman, and $\mathrm{H}_{2}$-temperature-programmed reduction (TPR) characterizations. The results revealed that the 3DOM NiCe samples preserved the three-dimensionally ordered macroporous channels with interlinked micro- or mesoporous structure and highly dispersed nickel oxide species in the framework upon different amount of nickel incorporation. In the evaluation of the oxidative dehydrogenation $(\mathrm{ODH})$ of propane, the 3DOM NiCe catalysts exhibited higher selectivity and yield to propene than the amorphous NiCe catalyst. An optimum yield of propene of $11.9 \%$ with the $30.3 \%$ propane conversion at $375^{\circ} \mathrm{C}$ was obtained over the 3DOM 2NiCe catalyst. Combining XRD, TPR, and Raman analysis, it could be found that the nickel incorporation in $\mathrm{CeO}_{2}$ lattice produced a high concentration of oxygen vacancies that were the active sites for the oxidative dehydrogenation of propane. Besides this, the 3DOM structure promoted the rapid diffusion of the reactants and products-favorable for the generation of propene in the ODH of propane.
\end{abstract}

Keywords: three-dimensionally; macroporous; NiCe; oxidative dehydrogenation; propane; propene

\section{Introduction}

The synthesis of propene from oxidative dehydrogenation $(\mathrm{ODH})$ of propane exhibits the virtue of favorable thermodynamics and less coke deposits compared with the traditional steam cracking of naphtha or direct dehydrogenation of propane, becoming one of the routes with the most potential to produce value-added unsaturated hydrocarbon chemicals [1,2]. In this process, vanadium and molybdenum-based catalysts are commonly used for the selective catalytic production of propene [3-5]. However, these catalysts are usually conducted at relatively higher temperatures (above $500{ }^{\circ} \mathrm{C}$ ), which cause the occurrence of undesirable combustion and then restrain propene formation. In the past few decades, great efforts have been dedicated to the improvement of vanadium and molybdenum-based ODH catalysts for highly preferable alkene yield [6-10], but propane conversion was normally 
unsatisfactory at the lower temperature of $400{ }^{\circ} \mathrm{C}$ using the catalysts above. Further studies are still required to develop highly active catalysts used under the mild reaction conditions in the ODH process.

In recent years, cerium-based materials doped with transition metal oxides (e.g., $\mathrm{Nb}_{2} \mathrm{O}_{3}, \mathrm{NiO}$ ) have been reported to favor the redox cycle in catalytic oxidation reactions by means of promoting the formation of anionic vacancies and surface oxygen species [11-14]. L. J. Duhamel [11] reported that $\mathrm{CeNi}_{0.5} \mathrm{O}_{\mathrm{Y}}$ catalyst could form cerium-nickel solid solution or interface of $\mathrm{NiO} / \mathrm{CeO}_{2}$, which presented many interaction sites between $\mathrm{Ce}$ and $\mathrm{Ni}$ cations, favorable for the good activation and selectivity in the oxidative dehydrogenation of propane under the mild temperature of ca. $350{ }^{\circ} \mathrm{C}$. Liu et al. [13] obtained a high yield of propene over Ni-Ce-O catalysts prepared by the gel-precipitation of oxalate precursor, and suggested that the highly dispersed nickel oxides contributed to the selective formation of propene in the ODH of propane. Despite the above advances, their practical application still remains particularly challenging. Due to the poor heat conductivity of the above Ni-Ce composite oxide catalysts, the strong exothermicity of the ODH reaction process may unavoidably induce hotspots in the reactor bed, which causes the catalyst's deactivation and restriction in industrial applications [15]. Therefore, it is worthwhile to pursue a catalyst that combines excellent catalytic performance with enhanced thermal conductivity and mass diffusion.

Recently, three-dimensional ordered macroporous (3DOM) materials have shown much benefit in use as catalysts, separation adsorbents, and photonic crystals $[16,17]$. These materials have a structure with regular large pore size and coadjacent macroporous channels with high approachable surface area, which ensure abundant exposure to the reactants. On the other hand, the three-dimensional transfixion pore structure is also beneficial to mass diffusion and improves the catalytic activity [18-23]. For example, $\mathrm{Au}$ embedded onto $3 \mathrm{DOM} \mathrm{CeO} 2$ exhibited excellent catalytic activity/selectivity in formaldehyde oxidation $[24,25]$. Using the beneficial features of $3 \mathrm{DOM} \mathrm{CeO}_{2}$, another study reported that the structured catalysts exhibit efficient heat/mass transfer with excellent activity, selectivity, and stability for the catalytic oxidation of methane to syngas [23].

However, to our best knowledge, few researchers have reported about the catalytic properties of three-dimensionally structured NiCe mixed oxides with ordered macroporous channels in the ODH reaction. Therefore, in the present research, we prepared 3DOM NiCe catalysts with different nickel loading by the assembly of the colloidal crystal template. The resulting catalysts were systematically characterized and evaluated in the $\mathrm{ODH}$ of propane for the purpose of understanding the effect of the nickel introduction on $\mathrm{ODH}$ activity of $3 \mathrm{DOM} \mathrm{CeO}_{2}$-doped $\mathrm{Ni}$ catalysts with respect to the modification of structure and redox properties.

\section{Results and Discussion}

\subsection{Morphology and Structure}

The $\mathrm{N}_{2}$ adsorption-desorption isotherms and the textural properties of 3DOM NiCe mixed oxides samples are given in Figure 1 and Table 1. The isotherms of all samples exhibit type IV adsorption isotherm patterns, which demonstrate the presence of the mesostructure. The 3DOM NiCe samples displayed a steep capillary condensation step at relatively higher pressures with H3-type hysteresis loops, suggesting the existence of the large mesoporous channel structure with a narrow range of sizes. The pure $\mathrm{CeO}_{2}$ and $2 \mathrm{NiCe}$ samples had $\mathrm{H} 4$ hysteresis loops, indicative of small channel-like mesopores in a broad range of sizes. Table 1 lists the detailed mesoporous sizes of the samples, which are consistent with $\mathrm{N}_{2}$ sorption isotherm analysis. Meanwhile, almost linear isotherms could be seen in the low-pressure portion for 3DOM NiCe samples, characteristic of the unrestrained monoor multilayer adsorption in macroporous structures [26]. From the pore-size distribution curves (Figure 1B) of these samples, it could be seen that the nanopore sizes of samples were dominantly distributed in the range of $2.5-4.5 \mathrm{~nm}$ with a peak value at $3 \mathrm{~nm}$. The second pores were mainly distributed between $7 \mathrm{~nm}$ and $70 \mathrm{~nm}$. The Brunauer-Emmett-Teller (BET) surface areas of the 3DOM $\mathrm{NiCe}$ samples ranged from $29 \mathrm{~m}^{2} / \mathrm{g}$ to $76 \mathrm{~m}^{2} / \mathrm{g}$ with the pore volume of $0.08-0.26 \mathrm{~cm}^{3} / \mathrm{g}$-larger 
than those $\left(13.8 \mathrm{~m}^{2} / \mathrm{g}\right.$ and $\left.0.06 \mathrm{~cm}^{3} / \mathrm{g}\right)$ of the nonporous bulk NiCe sample. It could be obviously observed that the samples showed larger pore sizes and larger BET surface areas with increasing $\mathrm{Ni} / \mathrm{Ce}$ ratio. Compared with the non-template prepared 2NiCe catalyst, 3DOM NiCe samples clearly demonstrated ample pore structures, which might contribute to the adsorption of reactant molecules and the diffusion of intermediate products, probably resulting in better catalytic performance [27].
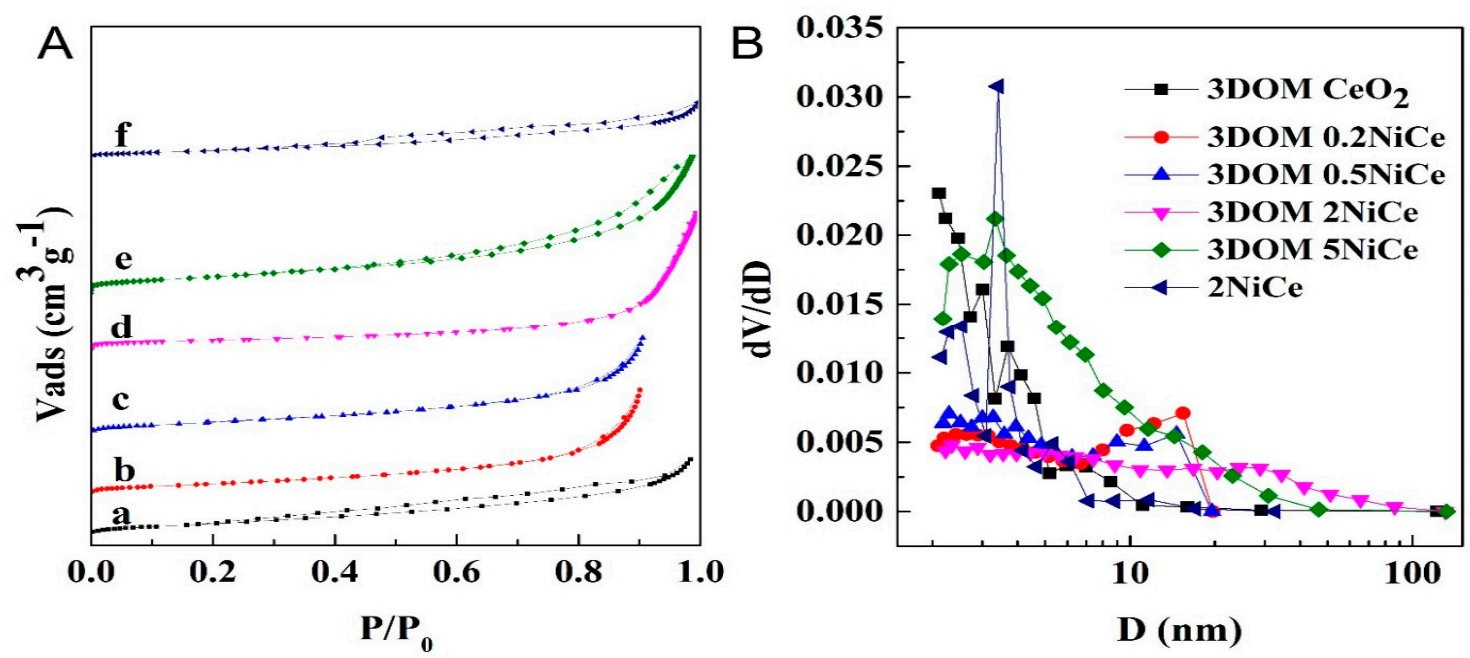

Figure 1. (A) $\mathrm{N}_{2}$ adsorption-desorption isomers of a-f: three-dimensional ordered macroporous (3DOM) $\mathrm{CeO}_{2}$, 3DOM 0.2NiCe, 3DOM 0.5NiCe, 3DOM 2NiCe, 3DOM 5NiCe, and 2NiCe and (B) Barrett-Joyner-Halenda (BJH) measurements of 3DOM CeO $2,3 \mathrm{DOM} 0.2 \mathrm{NiCe}, 3 \mathrm{DOM} 0.5 \mathrm{NiCe}, 3 \mathrm{DOM}$ 2NiCe, 3DOM 5NiCe, and 2NiCe.

Table 1. Textural parameters of the samples ${ }^{a}$.

\begin{tabular}{|c|c|c|c|c|c|}
\hline \multirow{2}{*}{ Samples } & \multicolumn{2}{|c|}{ Crystallite Size from XRD (nm) } & \multirow{2}{*}{$\mathrm{S}_{\text {BET }}\left(\mathrm{m}^{2} \mathrm{~g}^{-1}\right)$} & \multirow{2}{*}{$D_{p}(n m)$} & \multirow{2}{*}{$V_{P}\left(\mathrm{~cm}^{3} \mathrm{~g}^{-1}\right)$} \\
\hline & $\mathrm{CeO}_{2}(111)$ & $\mathrm{NiO}(200)$ & & & \\
\hline $3 \mathrm{DOM} \mathrm{CeO}_{2}$ & 12.8 & - & 29.2 & 6.8 & 0.08 \\
\hline 3DOM $0.2 \mathrm{NiCe}$ & 9.7 & - & 34.1 & 9.0 & 0.11 \\
\hline 3DOM $0.5 \mathrm{NiCe}$ & 9.2 & 14.8 & 37.3 & 11.0 & 0.15 \\
\hline 3DOM 2NiCe & 9.0 & 16.9 & 41.6 & 19.1 & 0.24 \\
\hline 3DOM 5NiCe & 8.8 & 12.9 & 76.04 & 9.6 & 0.26 \\
\hline $2 \mathrm{NiCe}$ & 10.6 & 17.9 & 13.8 & 7.4 & 0.06 \\
\hline 3DOM NiO & - & 15 & 49.17 & 15.4 & 0.21 \\
\hline
\end{tabular}

${ }^{\text {a }} \mathrm{S}_{\mathrm{BET}}$ : Brunauer-Emmett-Teller (BET) surface area; $\mathrm{D}_{\mathrm{p}}$ : pore diameter; $\mathrm{V}_{\mathrm{P}}$ : pore volume.

\subsection{TEM Images}

Figure 2 shows the transmission electron microscopy (TEM) and high resolution TEM (HRTEM) images of the samples. Apparently, the samples displayed macroporous channels with overlapped porous structure. As shown in Figure 2a1-e1, the macropore diameter sizes of 3DOM NiCe catalysts were about $190 \pm 10 \mathrm{~nm}$, and some voids were interlinked through hollow windows with a size of $60 \pm 10 \mathrm{~nm}$. The HRTEM images revealed the presence of a nanoporous wall, with nanopore sizes of 5-10 $\mathrm{nm}$ for the catalysts. This implied that the macroporous walls consisted of closely packed microporous or mesoporous structure. The existence of nano-pores in the skeletons of 3DOM NiCe samples caused the increase of the surface area, favorable for the reactant absorption and activation capability. The HRTEM images also displayed lattice fringes with a width of $0.3,0.19$, and $0.27 \mathrm{~nm}$ indexed as (111), (220), and (200) planes of $\mathrm{CeO}_{2}$, and of 0.26, 0.22, and $0.24 \mathrm{~nm}$ indexed as (101), (200), 
and (111) planes of $\mathrm{NiO}$, respectively. This indicated the co-existence of the crystal lattice of cerium and nickel oxides.

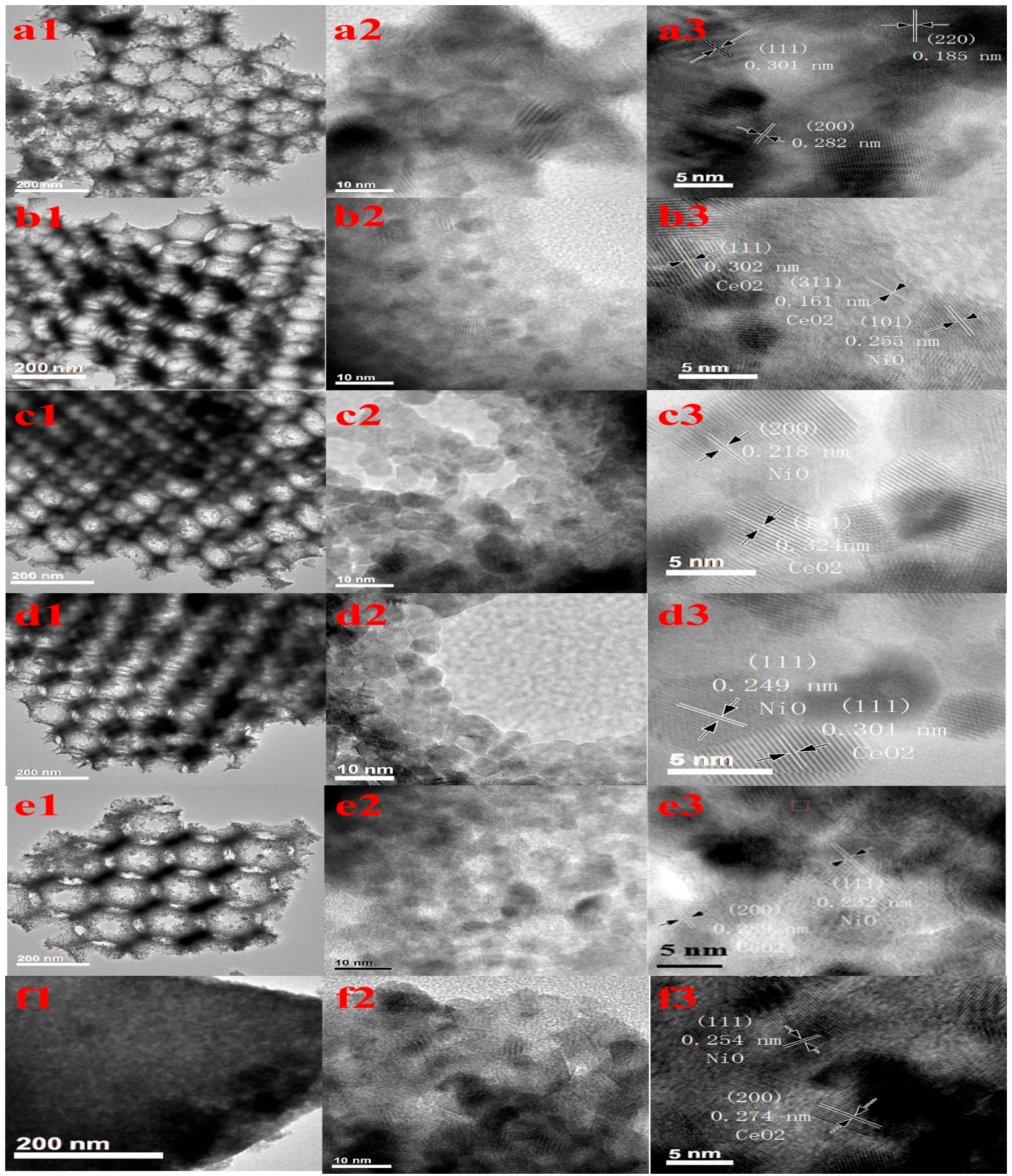

Figure 2. The TEM (left) and HRTEM (middle and right) images of the as-prepared 3DOM nickel-cerium samples: a1-a3 3DOM CeO $;$; b1-b3 3DOM 0.2NiCe; c1-c3 3DOM 0.5NiCe; d1-d3 3DOM 2NiCe; e1-e3 3DOM 5NiCe; and f1-f3 2NiCe.

\subsection{Powder X-ray Diffraction}

Figure 3 gives the diffraction patterns obtained with different 3DOM NiCe and 2NiCe catalysts. Only two crystallites - $\mathrm{NiO}$ and $\mathrm{CeO}_{2}$ - were observed, though the degree of crystallinity of the two phases strongly depended on the $\mathrm{Ni} / \mathrm{Ce}$ ratio. $\mathrm{NiO}$ diffraction lines disappeared for 3DOM $0.2 \mathrm{NiCe}$ catalyst, indicating the isomorphic substitution or high dispersion of nickel oxides on the surface of cerium oxides. Upon further increasing the $\mathrm{NiO}$ content, the bulk $\mathrm{NiO}$ phase could be seen from $\mathrm{X}$-ray diffraction (XRD). The broadness of the cerium peaks and the change of their position with the addition of nickel were observed, suggesting that partial $\mathrm{Ni}^{2+}$ cations replaced $\mathrm{Ce}^{4+}$ cations in the 
$\mathrm{CeO}_{2}$ lattice. Considering the smaller size of nickel ionic radius $\left(\mathrm{Ni}^{2+}: 0.07 \mathrm{~nm}\right)$ compared to that of cerium ionic radius $\left(\mathrm{Ce}^{4+}: 0.09 \mathrm{~nm}\right)$ [28], the above result could imply the generation of cerium-nickel solid solution, as reported in the literature [29].

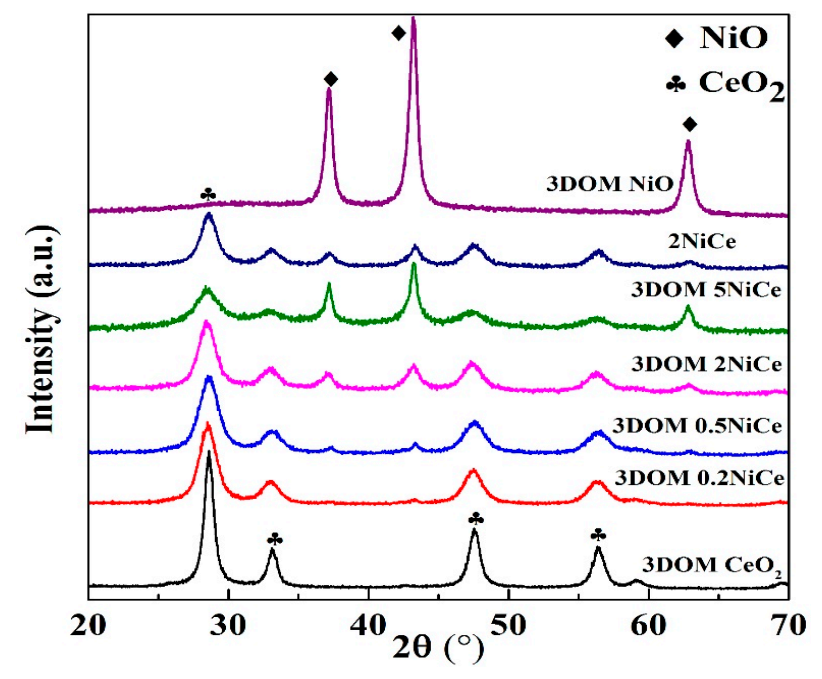

Figure 3. The X-ray diffraction (XRD) patterns of different catalysts.

The crystallite size could be calculated by the Scherrer formula based on the (200) and (111) characteristic XRD peaks of $\mathrm{NiO}$ and $\mathrm{CeO}_{2}$, respectively. From the concrete data listed in Table 1, NiCe mixed oxides showed the smaller crystal sizes of $\mathrm{NiO}$ and $\mathrm{CeO}_{2}$ than those of the corresponding pure oxides, which confirmed that the incorporation of $\mathrm{NiO}$ in $\mathrm{CeO}_{2}$ inhibited the growth of crystal particles. Additionally, the particle size of $\mathrm{NiO}$ and $\mathrm{CeO}_{2}$ in 3DOM NiCe mixed oxides were respectively in the ranges of 12.9-16.9 nm and 8.8-9.7 nm-less than those of the amorphous bulk NiCe sample $(17.9 \mathrm{~nm}$ and $10.6 \mathrm{~nm}$ ), indicating that $\mathrm{NiO}$ and $\mathrm{CeO}_{2}$ were well dispersed in the $3 \mathrm{DOM} \mathrm{NiCe}$ mixed oxides.

\subsection{Raman Spectra}

The Raman spectra of 3DOM NiCe and 2NiCe catalysts are shown in Figure 4. For comparison, the spectra of pure compounds of $\mathrm{CeO}_{2}$ and $\mathrm{NiO}$ were also demonstrated. The strong band designated to $\mathrm{F}_{2 \mathrm{~g}}$ mode was examined at $462 \mathrm{~cm}^{-1}$ for pure $\mathrm{CeO}_{2}$ [30]. Pure $\mathrm{NiO}$ showed a broad absorption peak centered at $503 \mathrm{~cm}^{-1}$, characteristic of the $\mathrm{Ni}-\mathrm{O}$ stretching mode in $\mathrm{NiO}$ [31,32].

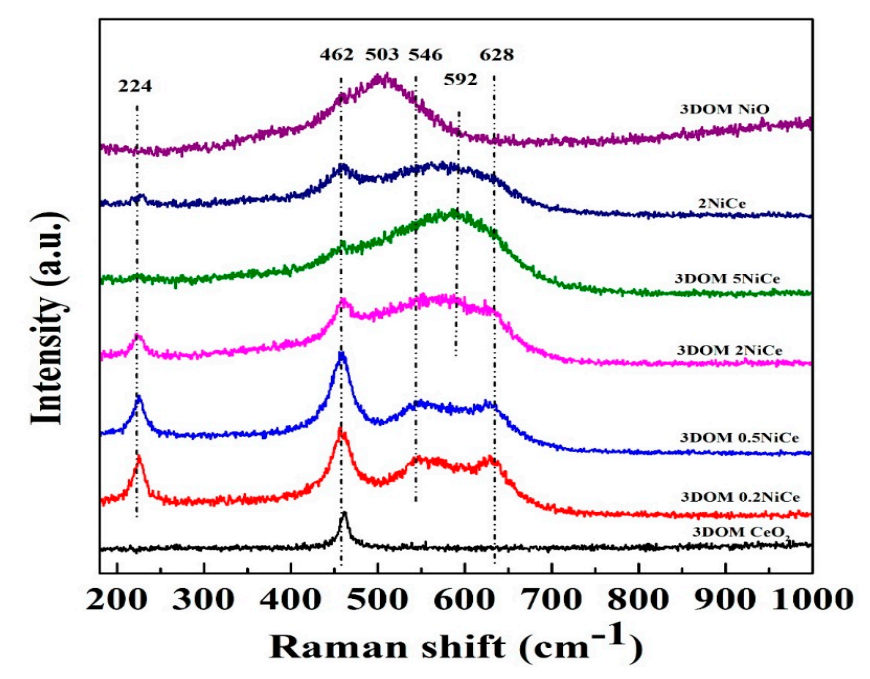

Figure 4. Raman spectra of the samples. 
It could be seen that the intensity of the $\mathrm{Ni}-\mathrm{O}$ stretching band decreased and the band associated with $\mathrm{CeO}_{2}$ phase slightly shifted to lower frequencies with the increasing incorporation of $\mathrm{Ni}$ amount for the 3DOM NiCe and 2NiCe samples. Such spectral changes were probably due to the similar isomorphous replacement of $\mathrm{Ni}^{2+}$ into the $\mathrm{CeO}$ lattice as revealed by Solsona [33]. Note that three bands at 224,592, and $628 \mathrm{~cm}^{-1}$ were obviously observed in the 3DOM NiCe catalysts, suggesting that further modification of the oxygen sublattice occurred and then promoted the formation of oxygen vacancies in $\mathrm{CeO}_{2}$ lattice as reported in the previous literature [30].

\subsection{Temperature-Programmed Reduction}

The reducibility of the samples was studied by $\mathrm{H}_{2}$-temperature-programmed reduction (TPR) (see Figure 5). Pure 3DOM NiO sample presented a broad reduction curve with two maxima at 432 and $516^{\circ} \mathrm{C}$, in accordance with the reduction of the surface nickel and the bulk nickel species in the framework of 3DOM structure, respectively. From the Gauss deconvolution of the $\mathrm{H}_{2}$-TPR patterns, three main reduction peaks (denoted T1, T2, and T3) could be seen in the temperature range of 100 to $700{ }^{\circ} \mathrm{C}$ for $3 \mathrm{DOM}$ Ni-Ce mixed oxides. The first reduction peak (T1) at around $308^{\circ} \mathrm{C}$ could be attributed to the replacement of $\mathrm{Ce}^{4+}$ by $\mathrm{Ni}^{2+}$ into $\mathrm{CeO}_{2}$ lattice [34]. Due to this, unbalanced charge distortion occurred; the Ni-O-Ce solid solution might be formed. As a result, the high concentration of oxygen vacancies was generated in $\mathrm{CeO}_{2}$ lattice due to the incorporation of $\mathrm{Ni}$ atoms. Such oxygen vacancies could participate in the redox cycle through adsorbing and activating the gaseous oxygen to form the active oxygen species. This coincided with the above XRD and Raman measurements. These reactive oxygen species can be reduced easily at low temperature, favorable for enhancing the catalytic performance of the catalysts. The second reduction peak (T2) centered at $370-410{ }^{\circ} \mathrm{C}$ for the $3 \mathrm{DOM}$ $0.2-5 \mathrm{NiCe}$ samples could be assigned to the reduction of the highly dispersed $\mathrm{NiO}$ species located on the surface layer of the $3 \mathrm{DOM}$ structure. The T3 peak in the $440-490^{\circ} \mathrm{C}$ temperature range might be identified as the high-temperature reduction peak of bulk $\mathrm{NiO}$ in the 3DOM framework as well as some strongly interacting nickel-cerium oxides. As for the 2NiCe sample, T1-T3 peaks corresponded to the reduction of surface active oxygen species adsorbed over oxygen vacancies, crystalline and $\mathrm{Ni}$ cations with a strong interaction with ceria, respectively [35].

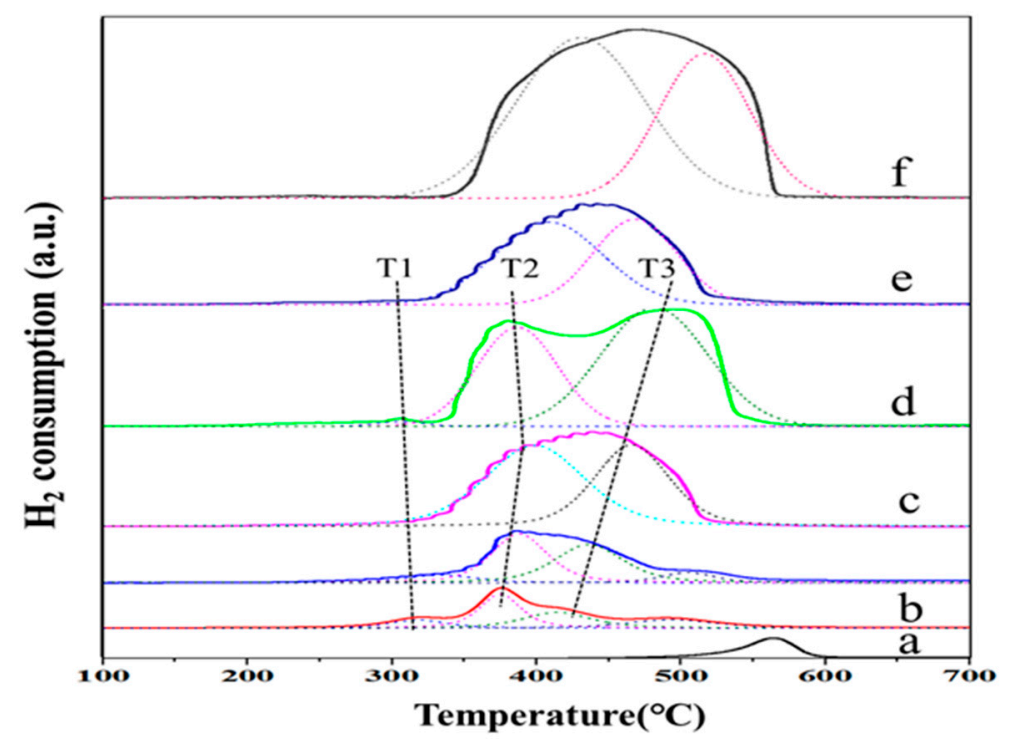

Figure 5. The $\mathrm{H}_{2}$-temperature-programmed reduction (TPR) patterns of the samples: (a) $3 \mathrm{DOM} \mathrm{CeO}_{2}$; (b) 3DOM 0.2NiCe; (c) 3DOM 2NiCe; (d) 3DOM 5NiCe; (e) 2NiCe, (f) 3DOM NiO.

Pure $3 \mathrm{DOM} \mathrm{CeO} 2$ showed only a wide and low intensity reduction peak centered at $564{ }^{\circ} \mathrm{C}$ in the investigated temperature range, correlated with the reduction of the surface ceria. Based on previous 
reports [33], the bulk ceria should be reduced by hydrogen above $700^{\circ} \mathrm{C}$; therefore, its reduction peak could not be observed in the present study. The reduction peak of the surface Ce-species for the NiCe catalysts were almost invisible, possibly due to such above surface reduction peak being overlapped by the more intense TPR profile of nickel species.

From the quantitative $\mathrm{H}_{2}$ consumption amount of the samples listed in Table 2, the pure 3DOM NiO showed the largest amount of $\mathrm{H}_{2}$ uptake $\left(13.3 \mathrm{mmol} \cdot \mathrm{g}^{-1}\right)$, close to the theoretical value $\left(13.4 \mathrm{mmol} \cdot \mathrm{g}^{-1}\right)$. By contrast, the lowest amount of $\mathrm{H}_{2}$ consumption $\left(2.7 \mathrm{mmol} \cdot \mathrm{g}^{-1}\right)$ over the $3 \mathrm{DOM} \mathrm{CeO}_{2}$ sample could be observed, which is far below the chemical stoichiometric amount of $11.6 \mathrm{mmol} \cdot \mathrm{g}^{-1}$. This indicated the nearly complete reduction of 3DOM NiO, while only a small number of $\mathrm{CeO}_{2}$ species could be reduced, coinciding with the above discussion. For 3DOM NiCe samples, $\mathrm{H}_{2}$ consumption amounts corresponding to the $\mathrm{T} 1$ peak was very small, and no obvious variation occurred with the change of $\mathrm{Ni} / \mathrm{Ce}$ ratio due to the relatively smaller amount of nickel cations incorporated in the $\mathrm{CeO}_{2}$ lattice. The major $\mathrm{H}_{2}$ uptake of $\mathrm{T} 2$ and $\mathrm{T} 3$ peaks was attributed to the reduction of surface and bulk nickel species that increased with the augment of the nickel amount-especially the T3 peak. This suggested that a greater proportion of bulk nickel species formed at higher nickel loading. Combining the TPR patterns (see Figure 5), it could also be seen that the main reduction maximum of the T2 peak generally shifted to higher temperature upon increasing $\mathrm{Ni} / \mathrm{Ce}$ ratio from 0.2 to 2 , and then moved to lower temperature after further enhancing the amount of nickel. This result might indicate that the reducibility of surface nickel oxide species displayed a decreasing trend during the change of the $\mathrm{Ni} / \mathrm{Ce}$ ratio range from $0.2-2$ and then went up at a $\mathrm{Ni} / \mathrm{Ce}$ ratio of 5 . The $\mathrm{T} 3$ reduction peak gradually shifted to higher temperature, probably due to the highly dispersed $\mathrm{NiO}$ or $\mathrm{Ni}-\mathrm{Ce}$ solid solution produced on $\mathrm{CeO}_{2}$ co-exist as reported by former researchers [35,36]. In terms of amorphous $2 \mathrm{NiCe}$ and $3 \mathrm{DOM}$ counterpart, the former presented a slightly greater $\mathrm{H}_{2}$ uptake and lower reduction maximum temperature, implying that the NiCe sample could be easily reduced without 3DOM structure.

Table 2. Hydrogen consumption of the temperature-programmed reduction (TPR) peaks for the various samples.

\begin{tabular}{|c|c|c|c|c|c|}
\hline \multirow{2}{*}{ Samples } & \multicolumn{4}{|c|}{$\mathrm{H}_{2}$ Consumption $\left(\mathrm{mmol} \cdot \mathrm{g}^{-1}\right)$} & \multirow{2}{*}{ 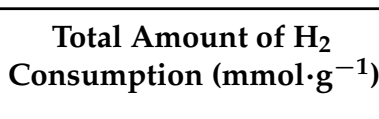 } \\
\hline & T1 Peak & T2 Peak & T3 Peak & $\mathrm{CeO}_{2}$ Peak & \\
\hline $3 \mathrm{DOM} \mathrm{NiO}$ & - & 8.3 & 5.0 & - & 13.3 \\
\hline $2 \mathrm{NiCe}$ & 0.1 & 4.6 & 3.3 & - & 8.0 \\
\hline 3DOM 5NiCe & 0.2 & 4.4 & 5.4 & - & 9.9 \\
\hline $3 \mathrm{DOM} 2 \mathrm{NiCe}$ & 0.1 & 3.9 & 3.8 & - & 7.8 \\
\hline 3DOM $0.5 \mathrm{NiCe}$ & 0.1 & 2.5 & 1.9 & 0.2 & 4.8 \\
\hline 3DOM 0.2NiCe & 0.1 & 1.8 & 1.1 & 0.5 & 3.5 \\
\hline $3 \mathrm{DOM} \mathrm{CeO}_{2}$ & - & - & - & 2.7 & 2.7 \\
\hline
\end{tabular}

\subsection{Catalytic Performance}

Table 3 lists the catalytic performance of the catalysts. The pure $\mathrm{CeO}_{2}$ had the lowest propane conversion, and the products were mainly $\mathrm{CO}_{2}$. For the $3 \mathrm{DOM}$ NiCe samples, the $\mathrm{Ni} / \mathrm{Ce}$ ratio exerted a great effect on the catalytic performances in the oxidative dehydrogenation of propane. The conversion of propane increased from $26.2 \%$ to $34.6 \%$ when the Ni/Ce ratio rose from 0.2 to 5 . The selectivity of propene increased from $28.8 \%$ to $39.4 \%$ when the Ni/Ce ratio increased from 0.2 to 2 . Upon further increasing the $\mathrm{Ni} / \mathrm{Ce}$ ratio up to 5 , a sharp decrease of propene selectivity could be observed over the 3DOM 5NiCe sample. Although 3DOM 2NiCe catalyst showed moderate propane conversion, it gave the best propene yield of $11.9 \%$. The distinct differences among the 3DOM NiCe and $2 \mathrm{NiCe}$ samples can be seen in Table 3. Compared with the 3DOM samples, the selectivity of propene over the nonporous $2 \mathrm{NiCe}$ catalyst was much lower, whereas the conversion of propane was higher than the former samples due to the greater degree of methane and $\mathrm{CO}_{2}$ formation. 
Table 3. Catalytic performance of the catalysts for the oxidative dehydrogenation (ODH) of propane at temperature $=375^{\circ} \mathrm{C}$, gaseous hourly space velocity $(\mathrm{GHSV})=15,000 \mathrm{~mL}(\mathrm{~g} \mathrm{~h})^{-1}$, molar ratio of $\mathrm{N}_{2}: \mathrm{C}_{3} \mathrm{H}_{8}: \mathrm{O}_{2}=8: 1: 1$.

\begin{tabular}{cccccc}
\hline \multirow{2}{*}{ Samples } & \multirow{2}{*}{ Propane Conversion (\%) } & \multicolumn{3}{c}{ Selectivity (\%) } & \multirow{2}{*}{ Propene Yield (\%) } \\
\cline { 3 - 5 } & & Propene & $\mathbf{C O}_{\mathbf{2}}$ & Crack $^{\mathbf{a}}$ & \\
\hline 2NiCe & 36.0 & 0.1 & 92.5 & 7.4 & 0.04 \\
3DOM 5NiCe & 34.6 & 0.2 & 97.7 & 2.1 & 0.06 \\
3DOM 2NiCe & 30.3 & 39.4 & 57.2 & 3.4 & 11.9 \\
3DOM 0.5NiCe & 27.3 & 38.3 & 57.3 & 4.4 & 10.5 \\
3DOM 0.2NiCe & 26.2 & 28.8 & 69.5 & 1.7 & 7.55 \\
3DOM CeO 2 & 7.2 & 22.9 & 76.8 & 0.3 & 1.65 \\
\hline
\end{tabular}

${ }^{\mathrm{a}}$ cracking products such as methane, ethylene, and ethane.

Considering the best catalytic performance of 3DOM 2NiCe catalyst listed in Table 3, we intensively investigated the catalytic performance of $3 \mathrm{DOM} 2 \mathrm{NiCe}$ catalyst and its amorphous counterpart of $2 \mathrm{NiCe}$ sample under the different reaction temperatures in the $\mathrm{ODH}$ of propane reaction (see Figure 6). For the amorphous $2 \mathrm{NiCe}$ sample, propane conversion increased monotonously with much lower propene yield during the increasing temperature course. Propene was the main product, with little $\mathrm{CO}_{2}$ produced at the initial stage of the reaction. However, $\mathrm{CO}_{2}$ selectivity sharply enhanced up to ca. $70 \%$ at the great expense of propene formation when the temperature rose above $320{ }^{\circ} \mathrm{C}$, indicating that the combustion of propane mainly occurred at higher temperature. Similar to the amorphous $2 \mathrm{NiCe}$ sample, the 3DOM $2 \mathrm{NiCe}$ catalyst demonstrated lower propane conversion and propene yield but higher propene selectivity below the reaction temperature of $320^{\circ} \mathrm{C}$. It seemed that $3 \mathrm{DOM} 2 \mathrm{NiCe}$ catalyst had less active property than the former sample. Note that a partial amount of propane conversion over the $2 \mathrm{NiCe}$ sample contributed to $\mathrm{CO}_{2}$ generation, while $3 \mathrm{DOM} 2 \mathrm{NiCe}$ catalyst exhibited a different reaction behavior favorable for propene formation at higher temperature. When the temperature increased in the range of $320-380^{\circ} \mathrm{C}$, the propane conversion and propene yield sharply increased with a relatively gentle decrease of propene selectivity. However, further increasing the reaction temperature above $380^{\circ} \mathrm{C}$, the propene selectivity and yield changed slightly with a mild increase of propane conversion. Although $\mathrm{CO}_{2}$ formation tenaciously increased, its selectivity was obviously lower with respect to that over the amorphous $2 \mathrm{NiCe}$ sample. This result led us to consider that the rapid diffusion/adsorption of propene in interconnected macropores of 3DOM $2 \mathrm{NiCe}$ catalyst avoided the deep oxidation of propene to form $\mathrm{CO}_{2}$ to a certain extent.
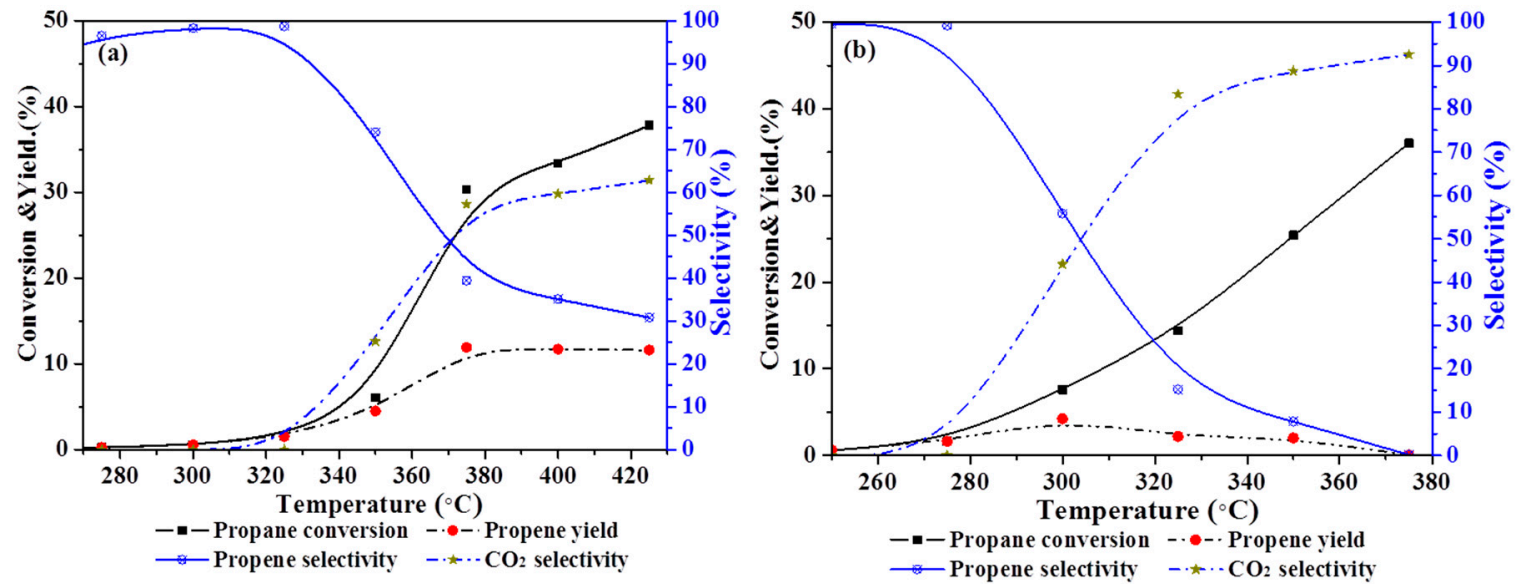

Figure 6. The changing curves of the catalytic performances as a function of temperature over the catalysts: (a) 3DOM 2NiCe; (b) 2NiCe. 


\subsection{Relationship between Catalyst Structure and Catalytic Performance}

3DOM NiCe oxides catalysts showed higher propane conversion and propene selectivity in the $\mathrm{ODH}$ of propane compared to pure $\mathrm{CeO}_{2}$. The conversion of propane rose with the increase of nickel content over the catalysts. These could be clarified from the redox properties of the catalysts. $\mathrm{H}_{2}-\mathrm{TPR}$ result revealed that the total reduced amount of nickel species of the samples descended in the order of $3 \mathrm{DOM} \mathrm{NiO}>3 \mathrm{DOM} 5 \mathrm{NiCe}>\ldots>3 \mathrm{DOM} 0.2 \mathrm{NiCe}$. It seemed that the catalytic activity was generally relevant to the rate of hydrogen extraction, which depends on the reducibility of the catalyst. On the other hand, according to the above XRD and Raman results, four phases over the catalysts could be observed: bulk $\mathrm{NiO}$, highly dispersed $\mathrm{NiO}_{x}, \mathrm{CeO}_{2}$, and a partial replacement of $\mathrm{Ni}^{2+}$ into $\mathrm{CeO}_{2}$, in which the highly dispersed $\mathrm{NiOx}$ as well as the surface area increased with the rise of nickel content. This may promote the propane conversion over the 3DOM NiCe catalysts.

In addition, the TPR results of 3DOM NiCe catalysts showed that the reducibility of nickel oxides species decreased with increasing Ni/Ce ratio from 0.2 to 2 . Meanwhile, the propene selectivity was enhanced during the same variation of nickel content. This might indicate that the formation of a larger amount of less-reducible Ni-sites favored the enhancement of propene selectivity. At the much higher nickel loading for 3DOM $5 \mathrm{NiCe}$ catalyst, a sharp decrease of propene selectivity could be observed, which was attributed to the propane combustion to $\mathrm{CO}_{2}$ due to the increasing bulk $\mathrm{NiO}$ over the catalyst. A similar behavior has also been observed over the $\mathrm{Nb}$-promoted $\mathrm{NiO}$ catalysts reported by Savova [32]. As for the comparison of the catalytic behaviors between 3DOM NiCe and 2NiCe catalysts, the highly dispersed nickel species on the 3DOM-structured catalyst enhanced the surface density of the framework oxygen vacancies as mentioned above that could obtain a larger amount of adjacent active sites, which transformed propane into propene more effectively and restricted the deep oxidation to $\mathrm{CO}_{2}$.

\section{Experimental}

\subsection{Preparation of the Catalyst}

3DOM NiCe catalysts were fabricated by a colloidal crystal templating procedure. During the typical synthesis of the catalysts, we first prepared the polystyrene (PS) colloidal crystal microspheres (diameters: ca. $380 \mathrm{~nm}$ ) in a soap-free emulsion, polymerized as in the literature approach [24,37]. Then, the PS colloidal crystals microspheres passed through centrifugation at $4000 \mathrm{rpm}$ for $4 \mathrm{~h}$ to obtain the suspended template. After removing the clear liquid, the solid material was dried at $60^{\circ} \mathrm{C}$, thus obtaining three-dimensional PS arrays with regularly ordered structure. A certain amount of citric acid, cerium, and nickel nitrate hydrate $\left(\mathrm{Ce}\left(\mathrm{NO}_{3}\right)_{3} \cdot 6 \mathrm{H}_{2} \mathrm{O}, \mathrm{Ni}\left(\mathrm{NO}_{3}\right)_{2} \cdot 6 \mathrm{H}_{2} \mathrm{O}\right)$ were dissolved in an ethanol and water (the final centration of ethanol was $95 \mathrm{vol} . \%$ ) mixture solution. The concentration of the metal ions was adjusted to $1 \mathrm{~mol} \cdot \mathrm{L}^{-1}$. Then, the PS arrays template was dropped into the solution and impregnated for $3 \mathrm{~h}$ to remove excess solution by vacuum filtration. The as-prepared wet solids were dried at $60^{\circ} \mathrm{C}$ overnight, and calcined in a furnace under an air flow at a temperature of $500{ }^{\circ} \mathrm{C}$ for $5 \mathrm{~h}$. The obtained 3DOM NiCe catalysts with different Ni contents were denoted as 3DOM xNiCe $(x=0,0.2,0.5,2,5)$, where $x$ represents the $\mathrm{Ni} / \mathrm{Ce}$ molar ratio. As a reference, $2 \mathrm{NiCe}$ sample without 3DOM structure was prepared by the same method without adding the PS hard template.

\subsection{Catalyst Characterization}

Surface areas were measured with the ASAP 2020 analyzer with the multipoint Brunauer-Emmett-Teller (BET) sorption method.

Transmission electron microscopy (TEM) images and high-resolution TEM (HRTEM) micrographs were obtained using a JEM-2100F (JEOL Ltd., Tokyo, Japan) and a field emission gun (FEG) F20 microscopes operated at $200 \mathrm{kV}$ and $300 \mathrm{kV}$, respectively.

Raman spectra were obtained on a Bruker Senterra dispersive Raman microscope with a laser wavelength of $532 \mathrm{~nm}$. 
Powder X-ray diffraction (XRD) was recorded on a Bruker diffractometer using $\mathrm{Cu} K \alpha$ radiation (40 kV and $40 \mathrm{~mA}$ ). Each sample was prepared by gently grinding to powder, and put into a quartz glass holder for measurement.

Temperature-programmed reduction (TPR) was performed using a Micromeritics chemisorption instrument. Before the reduction, $50 \mathrm{mg}$ of the catalyst was pretreated at $400{ }^{\circ} \mathrm{C}$ for $30 \mathrm{~min}$ under nitrogen stream with a flow rate of $30 \mathrm{~mL} \cdot \mathrm{min}^{-1}$. After cooling down to $80^{\circ} \mathrm{C}$, the sample was reduced by $5 \% \mathrm{H}_{2}$ in nitrogen with a flow rate of $50 \mathrm{~mL} \cdot \mathrm{min}^{-1}$ and heating rate of $10^{\circ} \mathrm{C} \cdot \mathrm{min}^{-1}$ from $80^{\circ} \mathrm{C}$ to $600{ }^{\circ} \mathrm{C}$.

\subsection{Catalytic Activity Measurements}

Catalytic test was carried out in an atmospheric pressure flow fixed-bed reactor (inner diameter $0.8 \mathrm{~cm})$ at $260-430{ }^{\circ} \mathrm{C}$. Then, $200 \mathrm{mg}$ of the catalyst was placed into the reactor with the feed gas stream of $\mathrm{O}_{2}: \mathrm{C}_{3} \mathrm{H}_{8}: \mathrm{N}_{2}=1: 1: 8$ (by volume) under total flow rate $\left(50 \mathrm{~mL} \cdot \mathrm{min}^{-1}\right)$. The products of the oxidative dehydrogenation of propane reaction were analyzed using gas chromatography with both flame ionization detector (FID) and thermal conductivity detector (TCD) detectors. The total carbon mass balance of each test was $100 \pm 3 \%$. Based on carbon mass balance, the conversion of $\mathrm{C}_{3} \mathrm{H}_{8}$ $\left(\mathrm{C}_{3} \mathrm{H}_{8 \text { conv }}\right)$ and the selectivity of $\mathrm{C}_{3} \mathrm{H}_{6}\left(\mathrm{C}_{3} \mathrm{H}_{6 \text { sel }}\right)$ were calculated according to the following equations:

$$
\begin{gathered}
\% \text { of } \mathrm{C}_{3} \mathrm{H}_{8 \text { conv }}=100 \times \frac{\mathrm{n}\left(\mathrm{C}_{3} \mathrm{H}_{8 \text { in }}\right)-\mathrm{n}\left(\mathrm{C}_{3} \mathrm{H}_{8 \text { out }}\right)}{\mathrm{n}\left(\mathrm{C}_{3} \mathrm{H}_{8 \text { in }}\right)} \\
\% \text { of } \mathrm{C}_{3} \mathrm{H}_{6 \text { sel }}=100 \times \frac{3 n\left(\mathrm{C}_{3} \mathrm{H}_{6 \text { out }}\right)}{3 \mathrm{n}\left(\mathrm{C}_{3} \mathrm{H}_{6 \text { out }}\right)+2 \mathrm{n}\left(\mathrm{C}_{2} \mathrm{H}_{6 \text { out }}\right)+2 \mathrm{n}\left(\mathrm{C}_{2} \mathrm{H}_{4 \text { out }}\right)+\mathrm{n}\left(\mathrm{CH}_{4 \text { out }}\right)+\mathrm{n}\left(\mathrm{CO}_{\text {out }}\right)+\mathrm{n}\left(\mathrm{CO}_{2 \text { out }}\right)}
\end{gathered}
$$

where $\mathrm{C}_{3} \mathrm{H}_{8 \text { in }}$ is the inlet feeding propane gas and $\mathrm{C}_{3} \mathrm{H}_{8 \text { out }}, \mathrm{C}_{3} \mathrm{H}_{6 \text { out }}, \mathrm{C}_{2} \mathrm{H}_{6 \text { out }}, \mathrm{C}_{2} \mathrm{H}_{4 \text { out }}, \mathrm{CH}_{\text {tout }}, \mathrm{CO}_{\text {out }}$, and $\mathrm{CO}_{2 \text { out }}$ are the outlet propane, propene, ethane, ethene, methane, carbon oxide and carbon dioxide, respectively.

\section{Conclusions}

3DOM NiCe catalysts with different $\mathrm{Ni} / \mathrm{Ce}$ molar ratios were fabricated by a colloidal crystal templating procedure. The obtained $\mathrm{NiCe}$ composite catalysts preserved three-dimensionally ordered macroporous channels with interlinked micro- or mesoporous structure. Compared with pure $\mathrm{CeO}_{2}$ catalyst, the prepared 3DOM NiCe catalysts possessed a larger amount of highly dispersed nickel species and oxygen vacancies in $\mathrm{CeO}_{2}$ lattice, which resulted in the synergetic $\mathrm{Ni}$-Ce interaction and more active oxygen species to participate the redox cycle. Among them, the 3DOM 2NiCe catalyst exhibited the maximum propene yield of about $11.9 \%$ at $30.3 \%$ propane conversion at a relatively lower temperature of $375^{\circ} \mathrm{C}$. The $3 \mathrm{DOM}$ samples displayed superior catalytic performances compared to the amorphous NiCe counterpart, indicating the potential application of the ordered macroporous structured materials in the ODH of propane.

Acknowledgments: The authors acknowledge the financial support from the projects of National Natural Science Foundation of China (21473230, 21603255), the Natural Science Foundation of Shanxi (201601D021052, 201701D221054) and the Shandong Natural Science Foundation (ZR2015BM018).

Author Contributions: Kegong Fang conceived the project; Lulu Liu, Mingwei Zhang performed the experiments; Lu Zhao, Juan Zhou, Wenbin Li, Xiaoliang Mu and Cheng Yang carried out the catalysts characterization and data analysis; Kegong Fang and Lulu Liu wrote the paper.

Conflicts of Interest: The authors declare no conflict of interest.

\section{References}

1. Chaar, M.A.; Patel, D.; Kung, M.C.; Kung, H.H. Selective oxidative dehydrogenation V-Mg-O of butane over catalysts. J. Catal. 1987, 105, 483-498. [CrossRef] 
2. Siew Hew Sam, D.; Soenen, V.; Volta, J.C. Oxidative dehydrogenation of propane over V-Mg-O catalysts. J. Catal. 1990, 123, 417-435. [CrossRef]

3. Murgia, V.; Farfán Torres, E.M.; Gottifredi, J.C.; Sham, E.L. Influence of concentration and order of aggregation of the active phases in $\mathrm{V}-\mathrm{Mo}-\mathrm{O}$ catalysts in the oxidative dehydrogenation of propane. Catal. Today 2008, 133-135, 87-91. [CrossRef]

4. Chen, M.; Wu, J.-L.; Liu, Y.-M.; Cao, Y.; Guo, L.; He, H.-Y.; Fan, K.-N. A practical grinding-assisted dry synthesis of nanocrystalline $\mathrm{NiMoO}_{4}$ polymorphs for oxidative dehydrogenation of propane. J. Solid State Chem. 2011, 184, 3357-3363. [CrossRef]

5. Cadus, L.E.; Ferretti, O. Characterization of Mo-MnO catalyst for propane oxidative dehydrogenation. Appl. Catal. A Gen. 2002, 233, 239-253. [CrossRef]

6. Liu, Q.; Li, J.; Zhao, Z.; Gao, M.; Kong, L.; Liu, J.; Wei, Y. Design, synthesis and catalytic performance of vanadium-incorporated mesoporous silica KIT-6 catalysts for the oxidative dehydrogenation of propane to propylene. Catal. Sci. Technol. 2016, 6, 5927-5941. [CrossRef]

7. Chen, S.; Ma, F.; Xu, A.X.; Wang, L.N.; Chen, F.; Lu, W.M. Study on the structure, acidic properties of V-Zr nanocrystal catalysts in oxidative dehydrogenation of propane. Appl. Surf. Sci. 2014, 289, 316-325. [CrossRef]

8. Solsona, B.; Blasco, T.; López Nieto, J.M.; Peña, M.L.; Rey, F.; Vidal-Moya, A. Vanadium oxide supported on mesoporous MCM-41 as selective catalysts in the oxidative dehydrogenation of alkanes. J. Catal. 2001, 203, 443-452. [CrossRef]

9. Cheng, M.-J.; Chenoweth, K.; Oxgaard, J.; Duin, A.V.; Goddard, W.A., III. Single-site vanadyl activation, functionalization, and reoxidation reaction mechanism for propane oxidative dehydrogenation on the cubic $\mathrm{V}_{4} \mathrm{O}_{10}$ cluster. J. Phys. Chem. C 2007, 111, 5115-5127. [CrossRef]

10. Wang, X.; Zhou, G.; Chen, Z.; Jiang, W.; Zhou, H. In-situ synthesis and characterization of V-MCM-41 for oxidative dehydrogenation of n-butane. Microporous Mesoporous Mater. 2016, 223, 261-267. [CrossRef]

11. Jalowiecki-Duhamel, L.; Ponchel, A.; Lamonier, C.; D’Huysser, A.; Barbaux, Y. Relationship between structure of $\mathrm{CeNi}_{\mathrm{x}} \mathrm{O}_{\mathrm{y}}$ mixed oxides and catalytic properties in oxidative dehydrogenation of propane. Langmuir 2001, 17, 1511-1517. [CrossRef]

12. Boizumault-Moriceau, P.; Pennequin, A.; Grzybowska, B.; Barbaux, Y. Oxidative dehydrogenation of propane on Ni-Ce-O oxide: Effect of the preparation method, effect of potassium addition and physical characterization. Appl. Catal. A Gen. 2003, 245, 55-67. [CrossRef]

13. Liu, Y.; Wang, L.; Chen, M.; Xu, J.; Cao, Y.; He, H.; Fan, K. Highly selective Ce-Ni-O catalysts for efficient low temperature oxidative dehydrogenation of propane. Catal. Lett. 2009, 130, 350-354. [CrossRef]

14. Li, T.; Wang, J.; Zhaorigetu, B.; Xu, A. Effect of preparation parameters on the catalytic performance of mesoporous $\mathrm{NiO}$ for the oxidative dehydrogenation of propane to propylene. Reac. Kinet. Mech. Cat. 2013, 110, 421-435. [CrossRef]

15. Zhang, Z.; Han, L.; Chai, R.; Zhang, Q.; Li, Y.; Zhao, G.; Liu, Y.; Lu, Y. Microstructured $\mathrm{CeO}_{2}-\mathrm{NiO}-\mathrm{Al}_{2} \mathrm{O}_{3} / \mathrm{Ni}$-foam catalyst for oxidative dehydrogenation of ethane to ethylene. Catal. Commun. 2017, 88, 90-93. [CrossRef]

16. Xie, S.; Deng, J.; Zang, S.; Yang, H.; Guo, G.; Arandiyan, H.; Dai, H. Au-Pd/3DOM Co $\mathrm{O}_{4}$ : Highly active and stable nanocatalysts for toluene oxidation. J. Catal. 2015, 322, 38-48. [CrossRef]

17. Ji, K.; Dai, H.; Deng, J.; Zang, H.; Arandiyan, H.; Xie, S.; Yang, H. 3DOM BiVO 4 supported silver bromide and noble metals: High-performance photocatalysts for the visible-light-driven degradation of 4-chlorophenol. Appl. Catal. B Environ. 2015, 168-169, 274-282. [CrossRef]

18. Xu, J.; Liu, J.; Zhao, Z.; Xu, C.; Zheng, J.; Duan, A.; Jiang, G. Easy synthesis of three-dimensionally ordered macroporous $\mathrm{La}_{1-\mathrm{x}} \mathrm{K}_{\mathrm{x}} \mathrm{CoO}_{3}$ catalysts and their high activities for the catalytic combustion of soot. J. Catal. 2011, 282, 1-12. [CrossRef]

19. Liu, Y.; Dai, H.; Du, Y.; Deng, J.; Zhang, L.; Zhao, Z.; Au, C.T. Controlled preparation and high catalytic performance of three-dimensionally ordered macroporous $\mathrm{LaMnO}_{3}$ with nanovoid skeletons for the combustion of toluene. J. Catal. 2012, 287, 149-160. [CrossRef]

20. Wei, Y.; Zhao, Z.; Li, T.; Liu, J.; Duan, A.; Jiang, G. The novel catalysts of truncated polyhedron Pt nanoparticles supported on three-dimensionally ordered macroporous oxides ( $\mathrm{Mn}, \mathrm{Fe}, \mathrm{Co}, \mathrm{Ni}, \mathrm{Cu}$ ) with nanoporous walls for soot combustion. Appl. Catal. B Environ. 2014, 146, 57-70. [CrossRef]

21. Lu, Y.; Cao, B.; Yu, F.; Liu, J.; Bao, Z.; Gao, J. High selectivity higher alcohols synthesis from syngas over three-dimensionally ordered macroporous Cu-Fe catalysts. ChemCatChem 2014, 6, 473-478. [CrossRef] 
22. Zheng, Y.; Li, K.; Wang, H.; Wang, Y.; Tian, D.; Wei, Y.; Zhu, X.; Zeng, C.; Luo, Y. Structure dependence and reaction mechanism of $\mathrm{CO}$ oxidation: A model study on macroporous $\mathrm{CeO}_{2}$ and $\mathrm{CeO}_{2}-\mathrm{ZrO}_{2}$ catalysts. J. Catal. 2016, 344, 365-377. [CrossRef]

23. Zheng, Y.; Li, K.; Wang, H.; Tian, D.; Wang, Y.; Zhu, X.; Wei, Y.; Zheng, M.; Luo, Y. Designed oxygen carriers from macroporous $\mathrm{LaFeO}_{3}$ supported $\mathrm{CeO}_{2}$ for chemical-looping reforming of methane. Appl. Catal. B Environ. 2017, 202, 51-63. [CrossRef]

24. Zhang, J.; Jin, Y.; Li, C.; Shen, Y.; Han, L.; Hu, Z.; Di, X.; Liu, Z. Creation of three-dimensionally ordered macroporous $\mathrm{Au} / \mathrm{CeO}_{2}$ catalysts with controlled pore sizes and their enhanced catalytic performance for formaldehyde oxidation. Appl. Catal. B Environ. 2009, 91, 11-20. [CrossRef]

25. Liu, B.; Liu, Y.; Li, C.; Hu, W.; Jing, P.; Wang, Q.; Zhang, J. Three-dimensionally ordered macroporous $\mathrm{Au} / \mathrm{CeO}_{2}-\mathrm{Co}_{3} \mathrm{O}_{4}$ catalysts with nanoporous walls for enhanced catalytic oxidation of formaldehyde. Appl. Catal. B Environ. 2012, 127, 47-58. [CrossRef]

26. Yan, H.W.; Blanford, C.F.; Holland, B.T.; Smyrl, W.H.; Stein, A. General synthesis of periodic macroporous solids by templated salt precipitation and chemical conversion. Chem. Mater. 2000, 12, 1134-1141. [CrossRef]

27. Ji, K.; Dai, H.; Deng, J.; Zhang, L.; Wang, F.; Jiang, H.; Au, C.T. Three-dimensionally ordered macroporous $\mathrm{SrFeO}_{3-\delta}$ with high surface area: Active catalysts for the complete oxidation of toluene. Appl. Catal. A Gen. 2012, 425-426, 153-160. [CrossRef]

28. Jalowiecki-Duhamel, L.; Pirez, C.; Capron, M.; Dumeignil, F.; Payen, E. Hydrogen production from ethanol steam reforming over cerium and nickel based oxyhydrides. Int. J. Hydrogen Energy 2010, 35, 12741-12750. [CrossRef]

29. Lamonier, C.; Ponchel, A.; D'Huysser, A.; Jalowiecki-Duhamel, L. Studies of the cerium-metal-oxygen-hydrogen system (metal $=\mathrm{Cu}, \mathrm{Ni})$. Catal. Today 1999, 50, 247-259. [CrossRef]

30. Reddy, B.M.; Khan, A.; Lakshmanan, P.; Aouine, M.; Loridant, S.; Volta, J.-C. Structural characterization of nanosized $\mathrm{CeO}_{2}-\mathrm{SiO}_{2}, \mathrm{CeO}_{2}-\mathrm{TiO}_{2}$, and $\mathrm{CeO}_{2}-\mathrm{ZrO}_{2}$ catalysts by XRD, Raman, and HREM techniques. J. Phys. Chem. B 2005, 109, 3355-3363. [CrossRef] [PubMed]

31. Heracleous, E.; Lemonidou, A.A. Ni-Nb-O mixed oxides as highly active and selective catalysts for ethene production via ethane oxidative dehydrogenation. Part I: Characterization and catalytic performance. J. Catal. 2006, 237, 162-174. [CrossRef]

32. Savova, B.; Loridant, S.; Filkova, D.; Millet, J.M.M. Ni-Nb-O catalysts for ethane oxidative dehydrogenation. Appl. Catal. A Gen. 2010, 390, 148-157. [CrossRef]

33. Solsona, B.; Concepción, P.; Hernández, S.; Demicol, B.; Nieto, J.M.L. Oxidative dehydrogenation of ethane over $\mathrm{NiO}-\mathrm{CeO}_{2}$ mixed oxides catalysts. Catal. Today 2012, 180, 51-58. [CrossRef]

34. Mahammadunnisa, S.; Manoj, K.P.; Lingaiah, N.; Subrahmanyam, C. NiO/Ce ${ }_{1-\mathrm{x}} \mathrm{Ni}_{\mathrm{x}} \mathrm{O}_{2-\delta}$ as an alternative to noble metal catalysts for CO oxidation. Catal. Sci. Technol. 2013, 3, 730-736. [CrossRef]

35. Bortolozzi, J.P.; Weiss, T.; Gutierrez, L.B.; Ulla, M.A. Comparison of $\mathrm{Ni}$ and $\mathrm{Ni}-\mathrm{Ce} / \mathrm{Al}_{2} \mathrm{O}_{3}$ catalysts in granulated and structured forms: Their possible use in the oxidative dehydrogenation of ethane reaction. Chem. Eng. J. 2014, 246, 343-352. [CrossRef]

36. Shan, W.; Luo, M.; Ying, P.; Shen, W.; Li, C. Reduction property and catalytic activity of $\mathrm{Ce}_{1-\mathrm{x}} \mathrm{Ni}_{\mathrm{x}} \mathrm{O}_{2}$ mixed oxide catalysts for $\mathrm{CH}_{4}$ oxidation. Appl. Catal. A Gen. 2003, 246, 1-9. [CrossRef]

37. Lu, L.; Li, L.; Hu, T.; Zhang, W.; Huang, X.; Zhang, J.; Liu, X. Preparation, characterization, and photocatalytic activity of three-dimensionally ordered macroporous hybrid monosubstituted polyoxometalate $\mathrm{K}_{5}\left[\mathrm{Co}\left(\mathrm{H}_{2} \mathrm{O}\right) \mathrm{PW}_{11} \mathrm{O}_{39}\right]$ amine functionalized titanium catalysts. J. Mol. Catal. A Chem. 2014, 394, 283-294. [CrossRef]

(C) 2018 by the authors. Licensee MDPI, Basel, Switzerland. This article is an open access article distributed under the terms and conditions of the Creative Commons Attribution (CC BY) license (http:/ / creativecommons.org/licenses/by/4.0/). 